\title{
LMTK2 regulates inflammation in lipopolysaccharide-stimulated BV2 cells
}

\author{
QIANYUN RUI $^{1}$, SHUGANG CAO ${ }^{2}$, XIAOZHU WANG $^{1}$, XIAOYU DUAN $^{1}$, XINYI IAO $^{1}$, \\ WANLI DONG ${ }^{1}$, QI FANG ${ }^{1,3}$, XUEGUANG ZHANG $^{4}$ and QUN XUE ${ }^{1,3,4}$
}

\author{
${ }^{1}$ Department of Neurology, The First Affiliated Hospital of Soochow University, Suzhou, Jiangsu 215006; \\ ${ }^{2}$ Department of Neurology, The Second People's Hospital of Hefei, Hefei, Anhui 230011; ${ }^{3}$ Suzhou Clinical Medical \\ Center of Neurology, Suzhou, Jiangsu 215004; ${ }^{4}$ Institute of Clinical Immunology, Jiangsu Key Laboratory of \\ Clinical Immunology, The First Affiliated Hospital of Soochow University, Suzhou, Jiangsu 215006 P.R. China
}

Received June 19, 2020; Accepted October 9, 2020

DOI: $10.3892 / \mathrm{etm} .2021 .9621$

\begin{abstract}
Microglia activation plays vital roles in neuroinflammatory pathologys. Lemurs tyrosine kinase 2 (LMTK2) was reported to regulate NF- $\mathrm{BB}$ signals. In the present study, the roles of LMTK2 were investigated in lipopolysaccharide (LPS)-treated BV-2 cells. Reverse transcription-quantitative (RT-q)PCR and western blotting (WB) were utilized to analyze LMTK2 levels in LPS-treated BV2 cells. MTT assay determined cell viabilities. Nitric oxide (NO) and prostaglandin E2 (PGE2) levels were assessed through Griess and enzyme-linked immunosorbent assay (ELISA), respectively. The expression level of inducible NO synthase (iNOS) and cyclooxygenase-2 $(\mathrm{COX}-2)$ were detected through RT-qPCR and WB. The release of inflammatory mediators under LPS stimulation, tumor necrosis factor- $\alpha$ (TNF- $\alpha$ ), interleukin-1 $\beta$ (IL-1 $\beta$ ), IL-6 and IL-10, were analyzed through ELISA. WB was used to analyze the nuclear factor erythroid 2-related factor 2 (Nrf2)/heme oxygenase 1 (HO-1)/NAD(P)H dehydrogenase quinone 1 (NQO1) signal pathway. The results showed that the levels of the inflammatory mediators, iNOS, NO, COX-2 and PGE2, along with pro-inflammatory factors, TNF- $\alpha$, IL-1 $\beta$ and IL- 6 , were significantly decreased following the induction of exogenous LMTK2 expression by LMTK2 overexpression plasmids in LPS-induced BV2 microglia. In contrast, anti-inflammatory factor IL-10 showed obvious decrease. Additionally, LMTK2 overexpression induced the elevation of $\mathrm{Nrf} 2$ in the cytoplasm and nucleus, along with the upregulation of HO-1 and NQO1 expression. In conclusion, LMTK2 is postulated to regulate neuroinflammation
\end{abstract}

Correspondence to: Dr Qun Xue, Department of Neurology, The First Affiliated Hospital of Soochow University, 188 Shizi Street, Suzhou, Jiangsu 215006, P.R. China

E-mail: author@mail.com

Key words: Lemurs tyrosine kinase 2, nuclear factor erythroid 2-related factor 2, inflammation, microglia possibly through Nrf2 pathway. The present study is essential to reveal the underlying function of LMTK2 and to identify novel therapeutic targets for drug development in treating neuroinflammation.

\section{Introduction}

Lemurs tyrosine kinase 2 (LMTK2) belongs to the transmembrane serine/threonine protein kinase family anchoring membrane with unique structure $(1,2)$. LMTK2, widely expressed in brain, is involved in regulating key cellular events, apoptosis and cell differentiation (3-7). According to a review, LMTK2 affects the sensitivities of cells to cytotoxicity depending on apoptotic and survival pathways (3). The latest research shows that LMTK2 can activate the NRF/ARE signaling pathway to reduce neurons injury induced by ischemia reperfusion (8). LMTK2 could be phosphorylated through CDK5/p35 in neurons, however, there is only a small amount of the phosphorylated forms of LMTK2 in non-neuron cells with inactive CDK5 (9-12). Furthermore, LMTK2 can exert vital roles through phosphorylating downstream targets in non-neuron cells (3). It has been proved that LMTK2 regulates NF- $\mathrm{KB}$ signals through the PP1/GSK3//p65 pathway or PP1/IKK pathway in colon cancer cells (13).

Neuroinflammation is associated with the progression of multiple neurological diseases. Microglia, as the main immune effector cells of the central nervous system (CNS), play a substantial role in CNS diseases (14). Although microglia have essential neuroprotection functions, including sensing changes of the environment, maintaining normal neuronal function and defensing these changes, they can damage neurons in response to a particular stimulus or with neuroinflammation (15). Activated microglia are involved in the pathologic processes of CNS diseases, such as neurodegenerative disease, pain, infection and brain trauma (16-19). The activation of microglia could damage neurons in the brain by releasing inflammatory cytokines and generating oxidative stress, which further triggers neurological diseases $(20,21)$. Therefore, the present study aims to explore the role of LMTK2 in lipopolysaccharide (LPS)-induced microglia inflammation and to explore whether it can activate Nrf2 signaling. LPS was used to activate 
mouse microglia (BV2) cells to construct a cell model of neuroinflammation.

\section{Materials and methods}

Cells. Mouse microglial cells, BV2, were purchased (The Institute of Cell Biology, Chinese Academy of Sciences, China) and cultured with DMEM, a high-glucose medium containing 10\% fetal bovine serum (Gibco; Thermo Fisher Scientific, Inc.), at a constant temperature of $37^{\circ} \mathrm{C}$ in $5 \% \mathrm{CO}_{2}$. The microglia were used in the experiment when the cells reached the logarithmic growth stage.

Western blotting $(W B)$. BV2 cell suspension was placed in a 6 -well plate $\left(2 \times 10^{5}\right.$ cells $\left./ \mathrm{ml}\right)$. The cells were stimulated with LPS at different concentrations $(100,200$ and $500 \mathrm{ng} / \mathrm{ml}$; Sigma-Aldrich; Merck KGaA) for $24 \mathrm{~h}$. For LMTK 2 overexpression, the cells were transfected with plasmids overexpressing LMTK2. After $24 \mathrm{~h}$, the cells were stimulated with LPS $(500 \mathrm{ng} / \mathrm{ml})$ for $24 \mathrm{~h}$. Subsequently, cells were collected to extract total protein using RIPA lysis solution (cat. no. R0278; Sigma-Aldrich; Merck KGaA). The protein concentrations were detected by BCA method. Then, $10 \%$ SDS-PAGE electrophoresis was performed to separate the proteins ( $40 \mu \mathrm{g}$ protein in each well). Skim milk powder (5\%) was utilized to block the PVDF membrane for $40 \mathrm{~min}$ at room temperature. Primary antibodies (LMTK2 (1:500; cat. no. DF3344; Affinity Biosciences), inducible nitric oxide synthase (1:1,000; iNOS; cat. no. ab178945; Abcam), cyclooxygenase 2 (1:1,000; COX2; cat. no. ab179800), nuclear factor erythroid 2-related factor 2 (1:1,000; NRF2; ab137550; Abcam), heme oxygenase-1 (1:2,000; HO-1; cat. no. ab189491; Abcam), NAD $(\mathrm{P}) \mathrm{H}$ dehydrogenase quinone 1 (1:20,000; NQO1; cat. no. ab28947; Abcam), Histone H3 (1:2,000; cat. no. ab1791; Abcam), GAPDH (1:5,000; cat. no. ab8245; Abcam) were incubated with the membrane at $4^{\circ} \mathrm{C}$ overnight. This was followed by incubation with the secondary antibodies goat anti-rabbit $\operatorname{IgG}(1: 10,000$; cat. no. ab6721; Abcam) and rabbit anti-mouse $\operatorname{IgG}(1: 10,000$; cat. no. ab6728; Abcam) at room temperature for $1 \mathrm{~h}$. ECL was used to visualize the protein bands which then was quantified with ImageJ $1.52 \mathrm{v}$ software (National Institutes of Health).

Plasmids transfection. The plasmids overexpressing LMTK2 were constructed by Shanghai GenePharma Co., Ltd. BV2 cells were seeded into 6 -well plates $\left(2 \times 10^{5}\right.$ cells $\left./ \mathrm{ml}\right)$. LMTK2 overexpression plasmids (Oe-LM; $4 \mu \mathrm{g}$ ) and empty plasmids (Oe-NC; $4 \mu \mathrm{g}$ ) were respectively transfected into BV2 cells using Lipofectamine ${ }^{\mathrm{TM}} 3000$ (Invitrogen; Thermo Fisher Scientific, Inc.) according to manufacturer's protocol. After transfection of $24 \mathrm{~h}$ at $37^{\circ} \mathrm{C}$, cells were activated by LPS $(500 \mathrm{ng} / \mathrm{ml})$.

Reverse transcription-quantitative (RT-q)PCR. BV2 cell suspension was placed in a 6 -well plate $\left(2 \times 10^{5}\right.$ cells $\left./ \mathrm{ml}\right)$. After experimental treatment, total RNA was extracted using TRIzol method and reverse transcribed into cDNA $42^{\circ} \mathrm{C}$ for $1 \mathrm{~h}$ (RevertaidTM First Strand cDNA Synthesis kit, Fermentas; Thermo Fisher Scientific, Inc.). Relative determination of LMTK2 and GADPH mRNA was performed by SYBR-Green dye method (Clontech Laboratories, Inc.) and calculated using the $2^{-\Delta \Delta \mathrm{Cq}}$ method (22). The primers of LMTK2 mRNA were as follows: Forward, 5'-TTGCCCGCCACAGTCTAAAC-3' and reverse, 5'-GATGACTCTTGCTACGCTAGT-3'; The primers of GADPH mRNA were as follows: Forward 5'-GCCTTCCGTGTTCCTACCC -3' and reverse 5'-TGCCTG CTTCACCACCTTC-3'. The target mRNA was amplified in the following thermocycling conditions: Predenaturation at $95^{\circ} \mathrm{C}$ for $3 \mathrm{~min} ; 30$ cycles of $95^{\circ} \mathrm{C} 30 \mathrm{sec}, 58^{\circ} \mathrm{C}$ for $30 \mathrm{sec}$ and $72^{\circ} \mathrm{C}$ for $1 \mathrm{~min}$. The total extension at $72^{\circ} \mathrm{C}$ for $10 \mathrm{~min}$.

MTT assay. Cells viability was detected as per the manufacturer's protocol. BV2 cells were seeded into 96-well plates $\left(1 \times 10^{5}\right.$ cells $\left./ \mathrm{ml}\right)$. After cells were treated, MTT solution of $5 \mathrm{~g} / \mathrm{l}$ (APExBIO Technology LLC) was added and placed in an incubator at $37^{\circ} \mathrm{C}$ and $5 \% \mathrm{CO}_{2}$ for $4 \mathrm{~h}$. The dimethyl sulfoxide (DMSO) solution of $100 \mu \mathrm{l}$ was added to each well. After shaking the mixture, the absorbance (A) value at the wavelength of $490 \mathrm{~nm}$ was detected by a microplate reader and the cell survival rate was calculated.

Griess assays. NO2 was formed from NO in aqueous and reacted with Griess reagent (Beyotime Institute of Biotechnology). Therefore, NO levels in the supernatant were indirectly detected. Cells were seeded into 24 -well plates $\left(2 \times 10^{5}\right.$ cells $\left./ \mathrm{ml}\right)$. After LPS treatment $(500 \mathrm{ng} / \mathrm{ml})$ for $24 \mathrm{~h}$, the supernatant in the medium was collected and then $50 \mu 1$ of Griess reagent was supplemented into the supernatant. After $10 \mathrm{~min}$, the absorbance at $540 \mathrm{~nm}$ was detected.

Enzyme-linked immunosorbent assay (ELISA). BV2 cells were cultured in 6-well plates $\left(2 \times 10^{5}\right.$ cells $\left./ \mathrm{ml}\right)$. After treatment, the supernatant in medium was collected. Interleukin (IL)-1 $\beta$, IL-6 and IL-10 levels were analyzed through ELISA kits (Mouse IL-1 $\beta$ ELISA kit; cat. no. PI301; IL-6, Mouse IL-6 ELISA kit; cat. no. PI326; and IL-10; Mouse IL-10 ELISA kit, cat. no. PI522; all from Beyotime Institute of Biotechnology), along with the detection of tumor necrosis factor (Mouse TNF- $\alpha$ ELISA Standard Recombinant Protein; cat. no. 29-8321-65; Invitrogen; Thermo Fisher Scientific, Inc.) and prostaglandin E2 (PGE2) levels (Prostaglandin E2 ELISA; ab133021; Abcam).

Statistical analysis. GraphPad Prism 8.0 software (GraphPad Software, Inc.) was used for statistical analysis of data, and one-way ANOVA was used to perform the comparison among groups, followed by Turkey's test. $\mathrm{P}<0.05$ was considered to indicate a statistically significant difference.

\section{Results}

LMTK2 was significantly decreased in LPS-induced $B V 2$ cells. LPS of different concentrations (100, 200 and $500 \mathrm{ng} / \mathrm{ml}$ ) was used to stimulate BV2 cells. The LMTK2 protein and mRNA levels presented a gradual decrease with the increasing dose of LPS (Fig. 1A and B). Therefore, $500 \mathrm{ng} / \mathrm{ml}$ LPS was utilized to perform the follow-up experiments. Subsequently, the plasmids Oe-LM and Oe-NC were utilized to pre-treat BV2 cells. A significant upregulation of LMTK2 mRNA levels was observed in cells transfected 
A
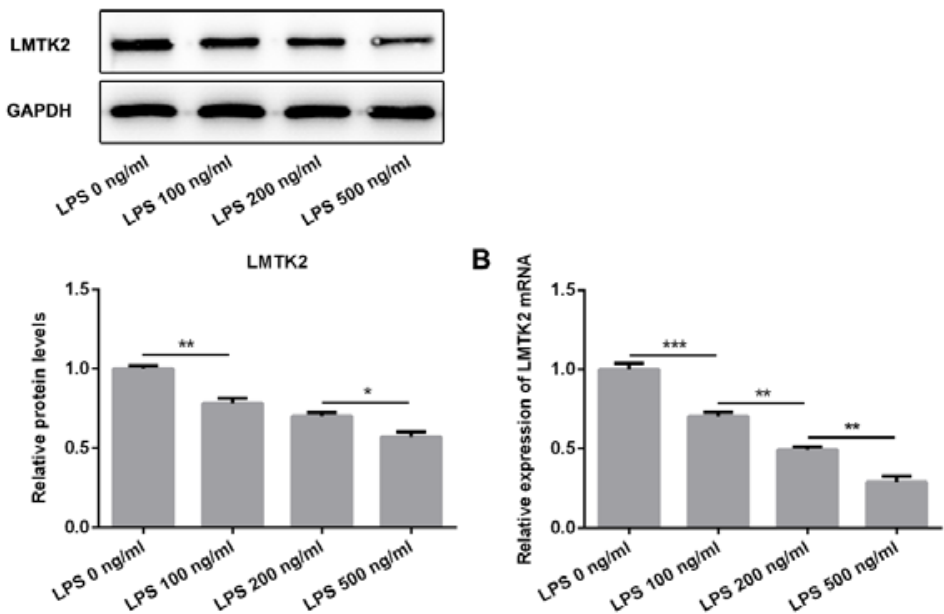

C
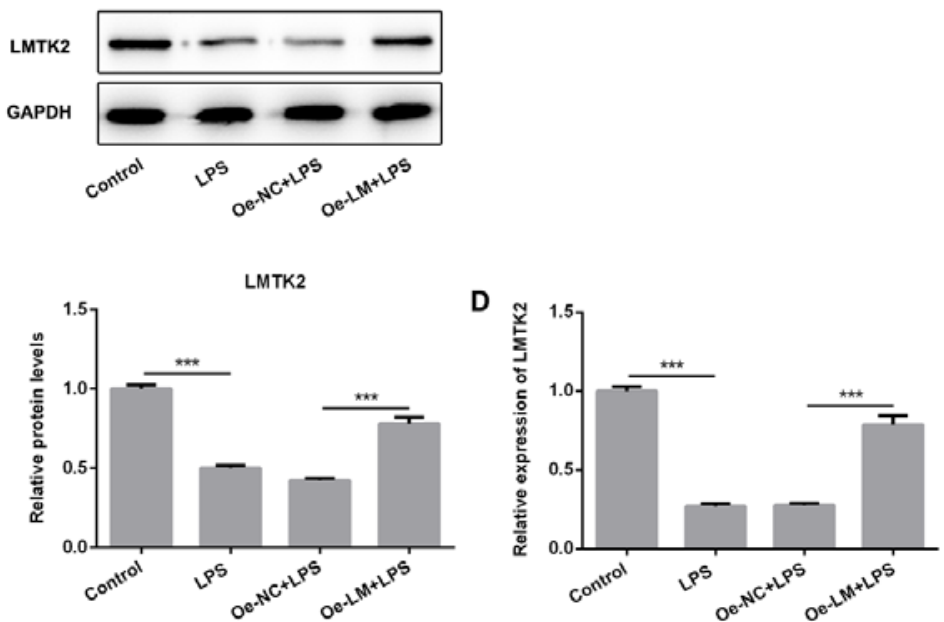

Figure 1. LPS stimulation decreased BV2 cell activities. (A and B) LMTK2 expression was analyzed through reverse transcription-quantitative PCR and western blot analysis in mouse BV2 cells stimulated by LPS at different concentrations (100, 200 and $500 \mathrm{ng} / \mathrm{ml})$. (C and D) LMTK2 levels were markedly increased through exogenous induction of LMTK2 expression. Data are presented as mean \pm SD of three independent experiments. ${ }^{*} \mathrm{P}<0.05 ;{ }^{* *} \mathrm{P}<0.01$; ${ }^{* * *} \mathrm{P}<0.001$. LMTK2, Lemurs tyrosine kinase 2; LPS, lipopolysaccharide 2; Oe-NC, negative control plasmid; Oe-LM, LMTK2-overexpression plasmid.

with Oe-LM. (Fig. S1). Following plasmid transfection for 24 h, LPS was used to activate BV2 cells. A marked upregulation of LMTK2 protein and mRNA levels was observed in BV2 cells transfected with Oe-LM compared with Oe-NC (Fig. 1C and D).

LMTK2 overexpression notably decreased the levels of pro-inflammatory mediators in LPS-stimulated BV2 cells. In subsequent experiments, cell viability was evaluated through MTT assay in BV2 cells stimulated with LPS. Compared with the control group,LPS stimulation increased the cell viability of BV2 cells (Fig. 2A). As shown in a previous study (23), the levels of cytoskeletal protein $\alpha$-tubulin and Iba1 were significantly increased in BV2 cells following LPS induction. Moreover, succinic acid dehydrogenase decreased exogenous MTT into water-insoluble blue-purple crystal formazan, contributing to the increase in OD value. In the present study, LMTK2 overexpression significantly decreased cell viability compared with cells treated with LPS alone (Fig. 2A). Subsequently, it was observed that the levels of proinflammatory mediators, consisting of NO generated by iNOS, PGE2 generated by COX-2), iNOS and COX-2, showed significant decreases in the presence of LMTK2 overexpression in LPS-activated BV2 cells (Fig. 2B-E).

The overexpression of LMTK2 regulated the release of inflammatory factors in LPS-induced BV2 cells. The levels of proinflammatory and anti-inflammatory factors were analyzed in LPS-treated BV2 cells with or without transfection of Oe-LM plasmids. As the result displayed, the proinflammatory mediators, TNF- $\alpha$, IL- $1 \beta$ and IL-6, were markedly decreased in response to LMTK2 overexpression compared with LPS treatment alone (Fig. 3A). Subsequently, Nrf2 signals were analyzed by detecting the expression of Nrf2 and its downstream genes (HO-1 and NQO1). Nrf2 was upregulated in the cytoplasm and nucleus, as well as HO-1 and NQO1, following overexpression of LMTK2 in BV cells (Fig. 3B), implying that the activation of Nrf2 is dependent on LMTK2.

\section{Discussion}

The present study showed that exogenous LMTK2 significantly upregulated the expression of $\mathrm{Nrf} 2$ in the 

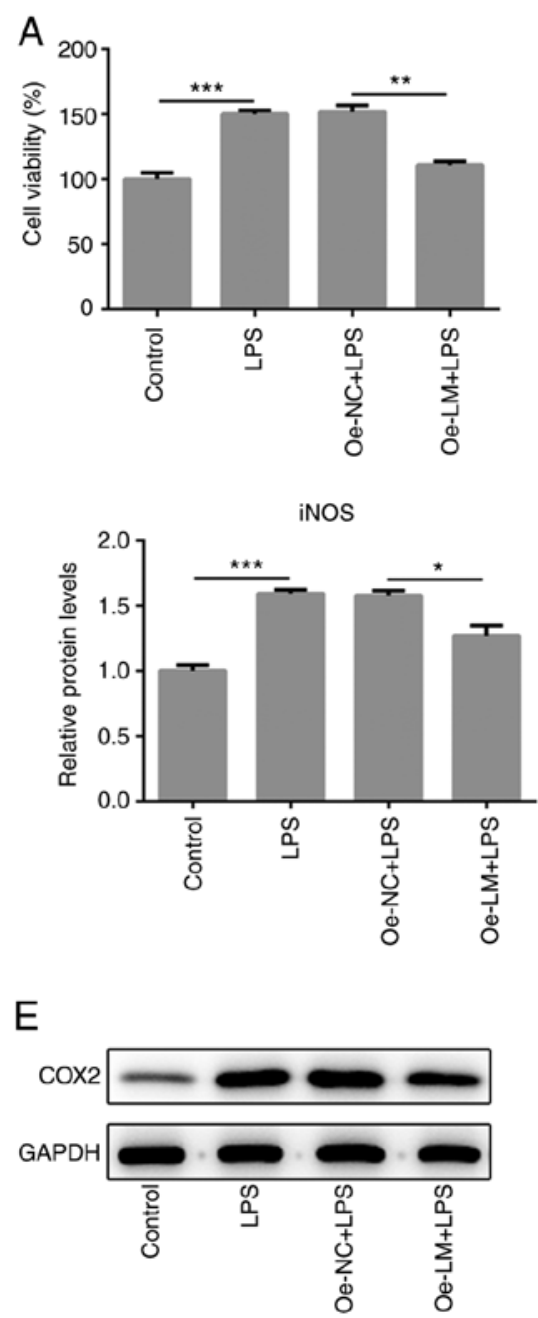

B
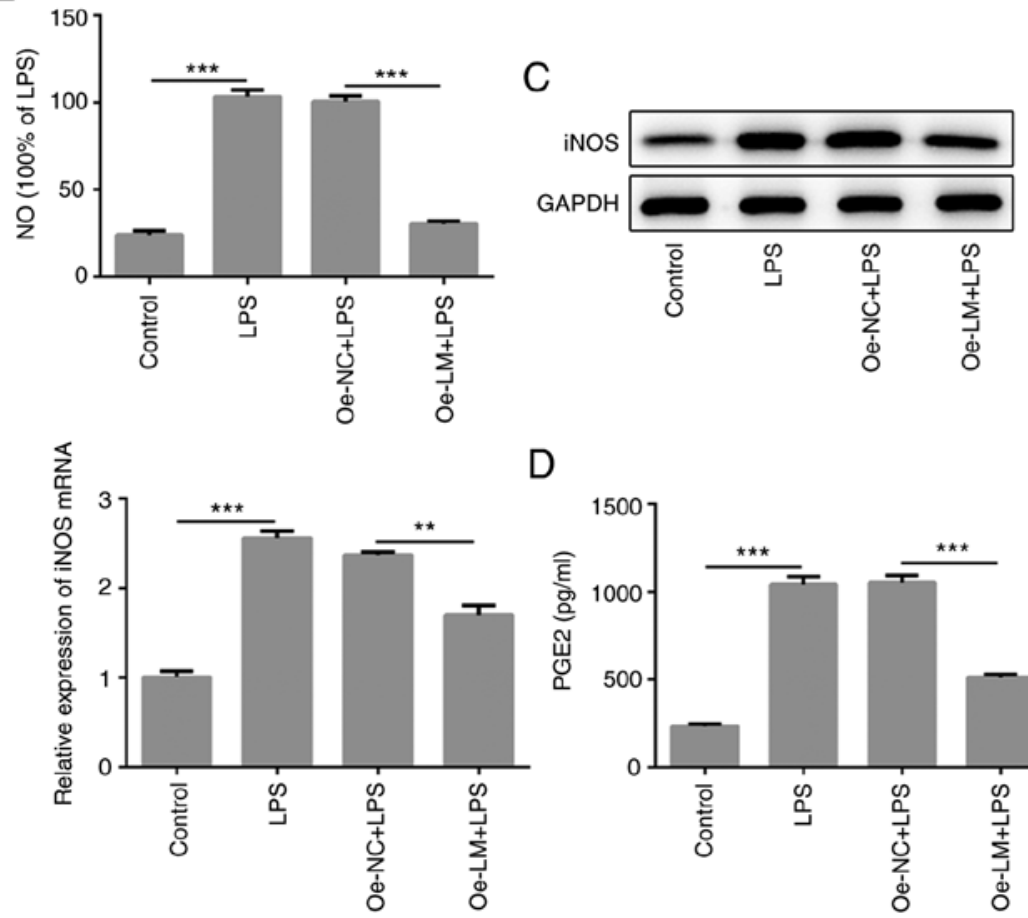

D
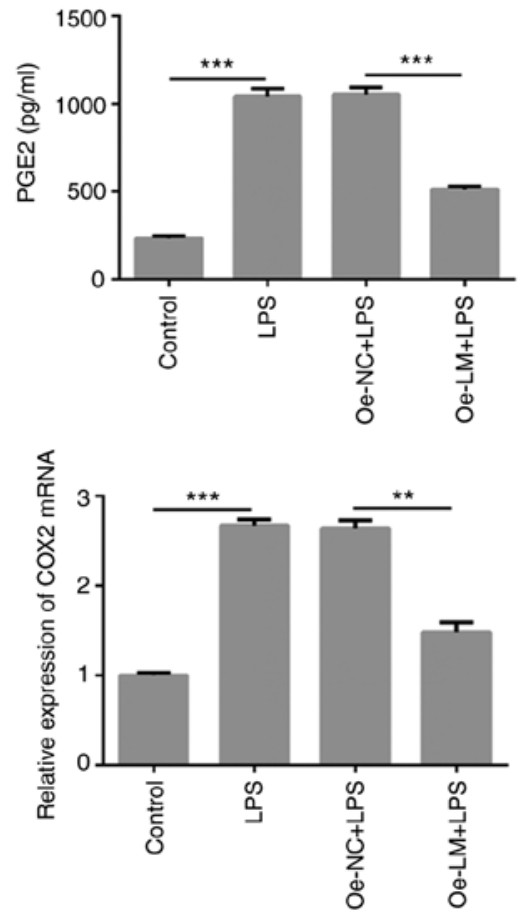

Figure 2. LMTK2 overexpression contributed to a reduction in the expression levels of pro-inflammatory mediators. (A) LMTK2 overexpression significantly decreased cell viability, as detected by MTT assay in LPS-induced BV2 cells. (B) Griess assays analyzed NO release in supernatant following LMTK2 overexpression in LPS-stimulated BV2 cells. (C) Reverse transcription-quantitative PCR and WB was used to evaluate the expression of iNOS in LPS-induced BV2 cells following LMTK2 overexpression. (D) PGE2 levels were markedly reduced, by WB analysis, in LPS-induced BV2 cells following LMTK2 overexpression. (E) LMTK2 overexpression significantly decreased COX2 expression in LPS-induced BV2 cells overexpressing LMTK2, by WB analysis. Data are shown as mean $\pm \mathrm{SD}$. Each experiment was repeated in triplicate. ${ }^{*} \mathrm{P}<0.05 ;{ }^{* *} \mathrm{P}<0.01 ;{ }^{* * * *} \mathrm{P}<0.001$. LMTK2, Lemurs tyrosine kinase 2 ; LPS, lipopolysaccharide 2 ; Oe-NC, negative control plasmid; Oe-LM, LMTK2-overexpression plasmid; WB, western blotting; NO, nitric oxide; iNOS, inducible nitric oxide synthase; PGE2, prostaglandin E2; COX2, cyclooxygenase 2.

nucleus and the levels of HO-1 and NQO1 proteins in BV2 cells stimulated with LPS; which implied that LMTK2 promoted the transcription of Nrf2-mediated downstream genes. A recent study demonstrated that LMTK2 regulates GSK-3 $\beta$ /Nrf2/ARE signaling to ameliorate neuronal injury induced by oxygen-glucose deprivation/reoxygenation (8).

There is a crosstalk between the Nrf and NF- $\kappa$ B pathways (24). Lack of Nrf2 is associated with enhanced production of cytokines (25), which could lead to the neurodegenerative changes in Nrf2 knockdown animals $(26,27)$. Previously, Nrf2 was reported to show anti-inflammatory abilities through the downregulation of COX-2, TNF $\alpha$ and iNOS in LPS-induced peritoneal macrophages (28). HO-1, as a Nrf2-mediated downstream protein, has been demonstrated to inhibit Nrf2-modulated NF- $\mathrm{B}$ (29). Collectively, the upregulation of HO-1 expression could suppress $\mathrm{NF}-\kappa \mathrm{B}$ activation and cause the decrease in pro-inflammatory factors in the present study. LPS treatment frequently induces the activation of NF- $\mathrm{B}$, along with the enhancement of iNOS, COX-2, PGE2 and pro-inflammatory factors in microglia cells $(30,31)$. PGE2 produced by microglial cells are the main source for neuroinflammation, showing marked increase upon LPS stimulation in microglia $(32,33)$.

The aforementioned studies imply that the Nrf2 pathway could negatively regulate the $\mathrm{NF}-\kappa \mathrm{B}$ pathway. Taken together, LMTK2 overexpression reduced the levels of iNOS, COX-2 and pro-inflammatory factors, TNF- $\alpha$, IL-1 $\beta$ and IL- 6 , but increased IL-10 level; possibly due to the dependence of LPS-induced microglia on Nrf2 pathway. However, no significant changes were observed in IL-10 levels following LPS stimulation, which was consistent with a previous report (34). IL-10 is an important inflammatory suppressor in vivo and 

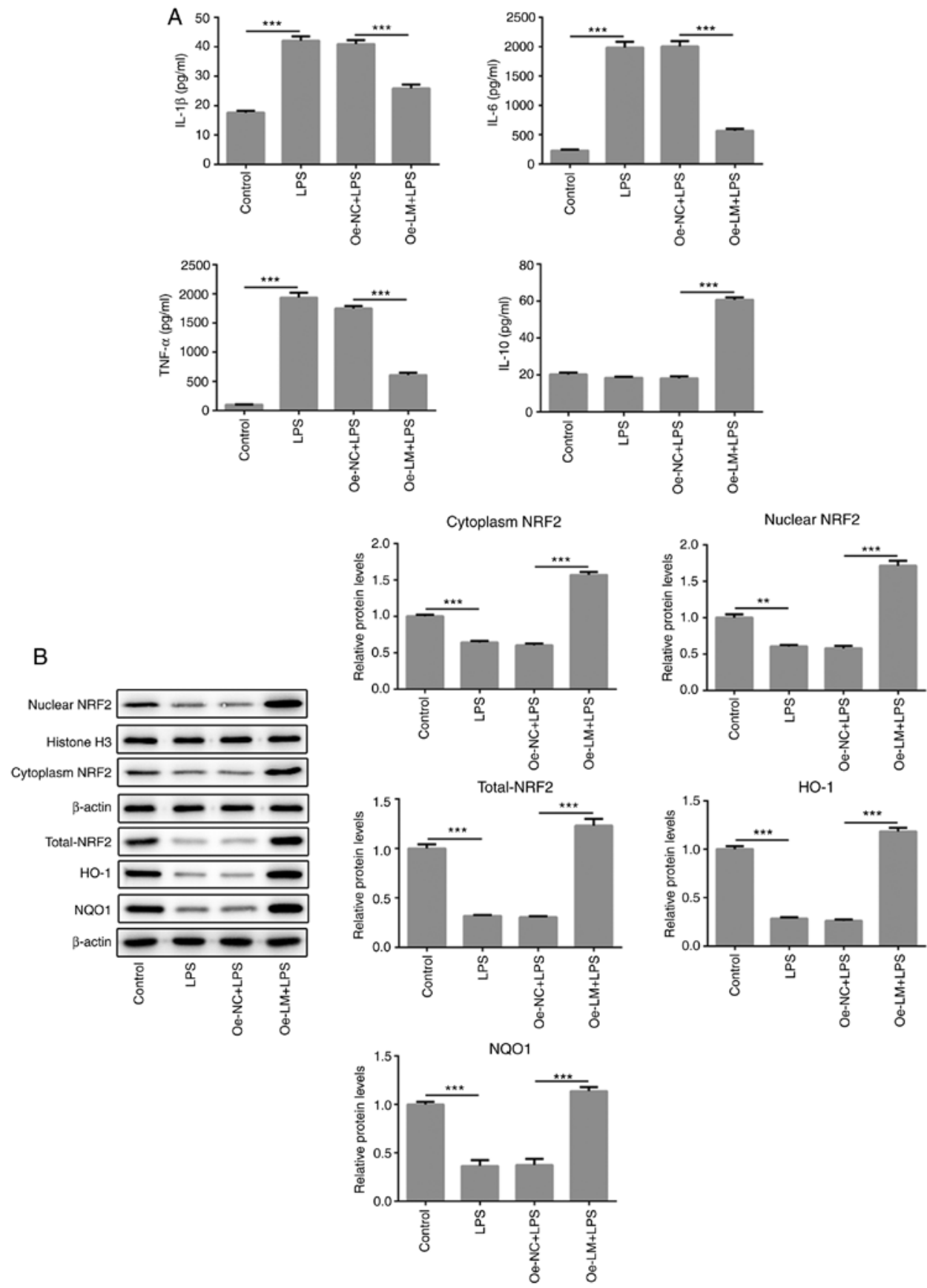

Figure 3. LMTK2 overexpression affected the release of inflammatory factors and Nrf2 pathway. (A) Inflammatory factors in cell supernatant were analyzed through enzyme-linked immunosorbent assay analysis in BV2 cells stimulated with LPS. (B) LMTK2 overexpression activated Nrf2 signal in LPS-stimulated microglia. Quantitation was performed based on three independent experiments and presented as the means $\pm \mathrm{SD}$. ${ }^{* *} \mathrm{P}<0.01$; ${ }^{* * *} \mathrm{P}<0.001$. LMTK2, Lemurs tyrosine kinase 2; LPS, lipopolysaccharide 2; Oe-NC, negative control plasmid; Oe-LM, LMTK2-overexpression plasmid; IL, interleukin; TNF, tumor necrosis factor; NRF2, nuclear factor erythroid 2-related factor 2; HO-1, heme oxygenase 1; NQO1, NAD(P)H dehydrogenase quinone 1.

can inhibit the release of pro-inflammatory cytokines in microglia cells in the central nervous system (35). Besides, LPS could induce the increase of NO, the production of iNOS, in microglia (36). In addition, $\mathrm{NF}-\kappa \mathrm{B}$ is considered upstream of NO and could initiate the synthesis of NO (37). A study has also shown that in lipoteichoic acid-induced microglia, matrix metalloprotease (MMP)-8 inhibitor regulates NF- $\kappa \mathrm{B}$ and Nrf2 signals (38). Thus, LPS-mediated increase in pro-inflammatory factors were markedly reduced by inducement of exogenous LMTK2 expression, which implied the involvement of LMTK2 in regulating MMP-8 levels; however, this requires further study. In conclusion, the present study implies that LMTK2 regulates inflammation potentially by activating Nrf2 pathway.

\section{Acknowledgements}

Not applicable.

\section{Funding}

No funding was received. 


\section{Availability of data and materials}

The datasets used and/or analyzed during the current study are available from the corresponding author on reasonable request.

\section{Authors' contributions}

QYR, and QX made substantial contributions to the conception and design of the study, acquired, analyzed and interpreted the data, and drafted and revised the manuscript for important intellectual content; QY, SGC, XZW, XYD, XI, WLD, QF and $\mathrm{XGZ}$ performed the experiments and interpreted the data. All authors read and approved the final manuscript.

\section{Ethics approval and consent to participate}

Not applicable.

\section{Patient consent for publication}

Not applicable.

\section{Competing interests}

The authors declare that they have no competing interests.

\section{References}

1. Tomomura M, Morita N, Yoshikawa F, Konishi A, Akiyama H, Furuichi T and Kamiguchi H: Structural and functional analysis of the apoptosis-associated tyrosine kinase (AATYK) family. Neuroscience 148: 510-521, 2007.

2. Wendler F: The LMTK-family of kinases: Emerging important players in cell physiology and disease pathogenesis. Biochim Biophys Acta Mol Basis Dis S0925-4439(18)30515-5, 2018.

3. Bencze J, Mórotz GM, Seo W, Bencs V, Kálmán J, Miller CCJ and Hortobágyi T: Biological function of Lemur tyrosine kinase 2 (LMTK2): Implications in neurodegeneration. Mol Brain 11: 20, 2018.

4. Wang $\mathrm{H}$ and Brautigan DL: A novel transmembrane Ser/Thr kinase complexes with protein phosphatase-1 and inhibitor-2. J Biol Chem 277: 49605-49612, 2002.

5. Luz S, Cihil KM, Brautigan DL, Amaral MD, Farinha CM and Swiatecka-Urban A: LMTK2-mediated phosphorylation regulates CFTR endocytosis in human airway epithelial cells. J Biol Chem 289: 15080-15093, 2014.

6. Kawa S, Ito C, Toyama Y, Maekawa M, Tezuka T, Nakamura T, Nakazawa T, Yokoyama K, Yoshida N, Toshimori K, et al: Azoospermia in mice with targeted disruption of the Brek/Lmtk2 (brain-enriched kinase/lemur tyrosine kinase 2) gene. Proc Natl Acad Sci USA 103: 19344-19349, 2006

7. Cruz DF, Farinha CM and Swiatecka-Urban A: Unraveling the Function of Lemur Tyrosine Kinase 2 Network. Front Pharmacol 10: 24, 2019.

8. Bao $\mathrm{H}$ and Gao M: Overexpression of lemur tyrosine kinase-2 protects neurons from oxygen-glucose deprivation/reoxygenation-induced injury through reinforcement of Nrf2 signaling by modulating GSK-3 $\beta$ phosphorylation. Biochem Biophys Res Commun 521: 964-970, 2020.

9. Manser C, Vagnoni A, Guillot F, Davies J and Miller CCJ: Cdk5/p35 phosphorylates lemur tyrosine kinase-2 to regulate protein phosphatase-1C phosphorylation and activity. J Neurochem 121: 343-348, 2012.

10. Tsai LH, Delalle I, Caviness VS Jr, Chae T and Harlow E: p35 is a neural-specific regulatory subunit of cyclin-dependent kinase 5 . Nature 371: 419-423, 1994.

11. Guidato S, Tsai LH, Woodgett J and Miller CC: Differential cellular phosphorylation of neurofilament heavy side-arms by glycogen synthase kinase- 3 and cyclin-dependent kinase-5. J Neurochem 66: 1698-1706, 1996.
12. Li BS, Zhang L, Gu J, Amin ND and Pant HC: Integrin alpha(1) beta(1)-mediated activation of cyclin-dependent kinase 5 activity is involved in neurite outgrowth and human neurofilament protein H Lys-Ser-Pro tail domain phosphorylation. J Neurosci 20: 6055-6062, 2000.

13. Zhang R, Li X, Wei L, Qin Y and Fang J: Lemur tyrosine kinase 2 acts as a positive regulator of NF- $\mathrm{KB}$ activation and colon cancer cell proliferation. Cancer Lett 454: 70-77, 2019.

14. Goldmann T and Prinz M: Role of microglia in CNS autoimmunity. Clin Dev Immunol 2013: 208093, 2013.

15. Hickman S, Izzy S, Sen P, Morsett L and El Khoury J: Microglia in neurodegeneration. Nat Neurosci 21: 1359-1369, 2018.

16. Lehnardt S: Innate immunity and neuroinflammation in the CNS The role of microglia in Toll like receptor mediated neuronal injury. Glia 58: 253-623, 2010.

17. Tsuda M, Tozaki Saitoh H and Inoue K: Purinergic system, microglia and neuropathic pain. Curr Opin Pharmacol 74-79, 2012.

18. Mao SS, Hua R, Zhao XP, Qin X, Sun ZQ, Zhang Y, Wu YQ, Jia MX, Cao JL and Zhang YM: Exogenous administration of PACAP alleviates traumatic brain injury in rats through a mechanism involving the TLR4/MyD88/NF- $\kappa$ B pathway. J Neurotrauma 29: 1941-1959, 2012.

19. Aravalli RN, Peterson PK and Lokensgard JR: Toll-like receptors in defense and damage of the central nervous system. J Neuroimmune Pharmacol 2: 297-312, 2007.

20. Hirsch EC and Hunot S: Neuroinflammation in Parkinson's disease: A target for neuroprotection? Lancet Neurol 8: 382-397, 2009.

21. Frank-Cannon TC, Alto LT, McAlpine FE and Tansey MG: Does neuroinflammation fan the flame in neurodegenerative diseases? Mol Neurodegener 4: 47, 2009.

22. Livak KJ and Schmittgen TD: Analysis of relative gene expression data using real-time quantitative PCR and the 2(-Delta Delta C(T)) Method. Methods 25: 402-408, 2001.

23. Gupta M and Kaur G: Aqueous extract from the Withania somnifera leaves as a potential anti-neuroinflammatory agent: A mechanistic study. J Neuroinflammation 13: 193, 2016.

24. Wardyn JD, Ponsford AH and Sanderson CM: Dissecting molecular cross-talk between Nrf2 and NF- $\kappa \mathrm{B}$ response pathways. Biochem Soc Trans 43: 621-626, 2015.

25. Pan H, Wang H, Wang X, Zhu L and Mao L: The absence of Nrf2 enhances NF- $\kappa \mathrm{B}$-dependent inflammation following scratch injury in mouse primary cultured astrocytes. Mediators Inflamm 2012: 217580, 2012.

26. Neymotin A, Calingasan NY, Wille E, Naseri N, Petri S, Damiano M, Liby KT, Risingsong R, Sporn M, Beal MF, et al: Neuroprotective effect of Nrf2/ARE activators, CDDO ethylamide and CDDO trifluoroethylamide, in a mouse model of amyotrophic lateral sclerosis. Free Radic Biol Med 51: 88-96, 2011.

27. Frakes AE, Ferraiuolo L, Haidet-Phillips AM, Schmelzer L, Braun L, Miranda CJ, Ladner KJ, Bevan AK, Foust KD, Godbout JP, et al: Microglia induce motor neuron death via the classical NF- $\kappa \mathrm{B}$ pathway in amyotrophic lateral sclerosis. Neuron 81: 1009-1023, 2014.

28. Lin W, Wu RT, Wu T, Khor TO, Wang H and Kong AN: Sulforaphane suppressed LPS-induced inflammation in mouse peritoneal macrophages through Nrf2 dependent pathway. Biochem Pharmacol 76: 967-973, 2008.

29. Soares MP, Seldon MP, Gregoire IP, Vassilevskaia T, Berberat PO, Yu J, Tsui TY and Bach FH: Heme oxygenase-1 modulates the expression of adhesion molecules associated with endothelial cell activation. J Immunol 172: 3553-3563, 2004.

30. Xie Q, Wu GZ, Yang N, Shen YH, Tang J and Zhang WD: Delavatine A, an unusual isoquinoline alkaloid exerts anti-inflammation on LPS-induced proinflammatory cytokines production by suppressing NF- $\mathrm{kB}$ activation in BV-2 microglia. Biochem Biophys Res Commun 502: 202-208, 2018.

31. Zhao J, Bi W, Xiao S, Lan X, Cheng X, Zhang J, Lu D, Wei W, Wang $\mathrm{Y}, \mathrm{Li} \mathrm{H}$, et al: Neuroinflammation induced by lipopolysaccharide causes cognitive impairment in mice. Sci Rep 9: 5790, 2019.

32. Jung YS, Park JH, Kim H, Kim SY, Hwang JY, Hong KW, Bae SS, Choi BT, Lee SW and Shin HK: Probucol inhibits LPS-induced microglia activation and ameliorates brain ischemic injury in normal and hyperlipidemic mice. Acta Pharmacol Sin 37: 1031-1044, 2016.

33. Saliba SW, Jauch H, Gargouri B, Keil A, Hurrle T, Volz N, Mohr F, van der Stelt M, Bräse S and Fiebich BL: Anti-neuroinflammatory effects of GPR55 antagonists in LPS-activated primary microglial cells. J Neuroinflammation 15: 322, 2018. 
34. Bao Y, Zhu Y, He G, Ni H, Liu C, Ma L, Zhang L and Shi D: Dexmedetomidine attenuates neuroinflammation in LPS-stimulated BV2 microglia cells through upregulation of miR-340. Drug Des Devel Ther 13: 3465-3475, 2019.

35. Cianciulli A, Dragone T, Calvello R, Porro C, Trotta T, Lofrumento DD and Panaro MA: IL-10 plays a pivotal role in anti-inflammatory effects of resveratrol in activated microglia cells. Int Immunopharmacol 24: 369-376, 2015.

36. Posadas I, Terencio MC, Guillén I, Ferrándiz ML, Coloma J, Payá M and Alcaraz MJ: Co-regulation between cyclo-oxygenase- 2 and inducible nitric oxide synthase expression in the time-course of murine inflammation. Naunyn Schmiedebergs Arch Pharmacol 361: 98-106, 2000.
37. El Moussawi L, Chakkour $M$ and Kreydiyyeh S: The epinephrine-induced PGE2 reduces $\mathrm{Na}^{+} / \mathrm{K}^{+}$ATPase activity in

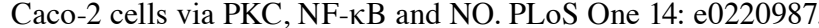
2019.

38. Lee EJ, Park JS, Lee YY, Kim DY, Kang JL and Kim HS: Anti-inflammatory and anti-oxidant mechanisms of an MMP-8 inhibitor in lipoteichoic acid-stimulated rat primary astrocytes: Involvement of NF- $\kappa \mathrm{B}, \mathrm{Nrf} 2$, and PPAR $-\gamma$ signaling pathways J Neuroinflammation 15: 326, 2018. 